\title{
Forming a Sense of Civic Responsibility in Youth Students
}

\section{Zyamil Gazizovich Nigmatov}

Kazan (Volga region) Federal University, Russian Federation, Republic of Tatarstan, 420008, Kazan, St. Kremlyovskaya, 18

\section{Ilnar Fagimovich Yarullin}

Kazan (Volga region) Federal University, Russian Federation, Republic of Tatarstan, 420008, Kazan, St. Kremlyovskaya, 18

\section{Doi:10.5901/mjss.2015.v6n3p336}

\section{Abstract}

This article examines the priority areas of the activity of colleges in terms of the civic-patriotic education of students and factors impacting on the development of a sense of civics in youth students. The authors propound a model for the development of a sense of civic responsibility in college students, propose pedagogical conditions that would ensure the effectiveness of formation of a sense of civic responsibility in students, and bring to light the major forms, methods, and means of the civil making of the student's personality.

Keywords: civics, patriotism, education/bringing-up, college, educational space, students, pedagogical model, pedagogical conditions

\section{Introduction}

Despite the fact that at present there are numerous studies dedicated to the issue of civic education (mainly in the area of school education), there has been a lack of research concerning issues related to the formation of a sense of civic responsibility in youth students. What makes the issue of the civic education of students more topical is that we are currently observing:

- the orientation of the content of civic education towards legal education with the personality-oriented aspects of civil behavior being ignored - the ideals and principles of civics, the spiritual-moral criteria of social life, a humane attitude towards cultural differences between and the traditions of various peoples, and the ability to perceive a specific life situation and act accordingly, etc.;

- the lack of a clear-cut methodology for educating youth students, which would meet the challenges of changed social conditions, and the lack of a proper system of the moral and material encouragement of college instructors for carrying out educative work among students.

This is attested to by a whole range of contradictions: between society's imperious need in youth with a developed civil culture and the insufficient degree to which mechanisms that would help to successfully resolve this issue in the setting of college education have been worked out; between the orientation of the very system of higher education towards resolving issues in the formation of professional competencies and the need to concurrently resolve the objectives of fostering a civic culture in youth students (in scientifically organized educative work), etc.

The article "The Importance of Civic Education", published in the magazine "Democracy and Society", stresses that "in many ways this focus on civil society is well deserved, since public awareness and activity play a critical role in any functioning democracy" [1]. Furthermore, "civic education in a democratic society most assuredly needs to be concerned with promoting understanding of the ideals of democracy and a reasoned commitment to the values and principles of democracy" [2]. The same thought has been accentuated in Russian encyclopedic dictionaries: "the primary aim of civic education is to nurture in people the moral ideals of society, a sense of love for one's homeland, the need to act for the benefit of society, etc." [3].

This article aims to: bring to light the essence of the term "students' civic responsibility", identify factors in, particular forms of, and methods for, and work out a model and propose pedagogical conditions for the formation of a sense of civic responsibility in present-day youth students. 


\section{Methods}

This study's methodological basis is grounded in: the theory of human development and its dependence on natural and social factors, the axiological and personal-activity approaches, and the principle of the unity of consciousness and activity.

To resolve the objectives set, the authors have employed the following methods: comparative and logical analysis, synthesis, generalization, modeling, study and generalization of the innovation experience of colleges in terms of fostering civic responsibility in students, conversation, questionnaires, goal-oriented observations of the activity of youth students, mathematical statistics methods, and conducting a pedagogical experiment on fostering civic responsibility in the setting of specific colleges. In the summative stage of the experiment, the authors determined the degree of development of civic responsibility in students, based on which there were formed an experimental (61 students) and a control (66 students) groups. The overall number of trial subjects was 127 individuals. The experiment's formative stage involved work on implementing in the education/bringing-up process the pedagogical conditions for the formation of a sense of civic responsibility in students, which were identified as a result of the study. In the experiment's control stage, the authors performed final work on comparing initial data obtained, determined the development level of civic responsibility attained by the students over the course of the experiment, and conducted a comparative analysis of data obtained at various diagnostic stages.

The results of sections on the study of the degrees to which a sense of civic responsibility was formed in students substantiated the correctness of the hypothesis put forward: the indicators of the development of civic responsibility in students within the control group remained almost unchanged, whereas they increased in the experimental group.

The assessment of the pedagogical process on the development and formation of a sense of civic responsibility also included the analysis of information on the state of educative work, which was provided by the Dean's office, the student body of the academic group, the curator, the heads of various scientific-creative collectives, study groups, and sports groups. The collection of information was conducted by the group's curator.

\section{Main Part}

As we know, the period of attending college is the most important in the process of formation of personality. Along with the acquisition of general and special knowledge, students develop not only their first professional competencies and skills but a corresponding system of values. As a social-demographic group, the youth of today possess high social mobility, are a source of innovations, and are most susceptible to them. Yet, the lack of life experience is reflected in that the culture of responsible civic behavior is poorly developed within the youth environment of today [4].

In this regard, we ought to pay the most meticulous attention to issues related to the development of civics in students in the process of their professional preparation in college.

The terms "citizen", "civil society", "civic education/bringing-up", and "civic responsibility" were basic in identifying factors and conditions for the formation of a sense of civic responsibility in students. According to "A Dictionary of Law", "a citizen is a person that belongs to a particular state on a legal basis. He/she possesses political rights and liberties. It is apparent that civic responsibility can exist within a civil society. A civil society is an aggregate of relations in the sphere of economics, culture, etc., which develop within a democratic society independent and autonomous of the state" [5].

Margaret Stimmann Branson, Associate Director of the Center for Civic Education in Calabasas, CA, writes in her article "The Role of Civic Education": "Civic education, therefore, is - or be should be - a prime concern.... It is imperative, therefore, that educators, policymakers, and members of civil society make the case and ask for the support of civic education from all segments of society and from the widest range of institutions and governments" [6]. For "good civic education develops skills, such as deliberation, collaboration, and public-speaking, however, achieving those outcomes requires more challenging standards for civics and better integration with other disciplines" [7].

In foreign literature, we also find the following definition of a key term: "In its broadest definition, "civic education" means all the processes that affect people's beliefs, commitments, capabilities, and actions as members or prospective members of communities. Civic education need not be intentional or deliberate; institutions and communities transmit values and norms without meaning to" [8].

In her article "Civic Education. What is It?", Jennifer Rietbergen-McCracken writes: "The overall goal of civic education is to promote civic engagement and support democratic and participatory governance" [9].

Civics is "an essential characteristic of a person and his/her activity as a human being with a civic mindset, an active civic attitude, patriotic feelings, and experience of publicly beneficial activity" [10]. Civic responsibility is a personal quality that includes moral-value, intellectual, emotional-volitional, operational, and reflexive components and reflects the 
student's readiness to display a responsible civic attitude in the form of deeds, behavior, lifestyle, and way of living in present-day society.

During the course of the study, the authors worked out a model for the formation of a sense of civic responsibility, which is construed as an algorithm for constructing and organizing the effective ensuring of the educational process in terms of fostering civic responsibility in students, which could be realized at institutions of higher professional learning.

For the description of the model for fostering civic responsibility in students, the systemic approach was employed. Viewing the process of formation of a sense of civic responsibility in students as a complex multi-tiered system whose component parts are the elements of the educational process of an institution of higher professional learning, the authors marked out the following major components in it: target-related, organizational, content-related, and result-related. All the components of the model for the formation of a sense of civic responsibility in pedagogical college students are interrelated and form a unity (Figure 1).

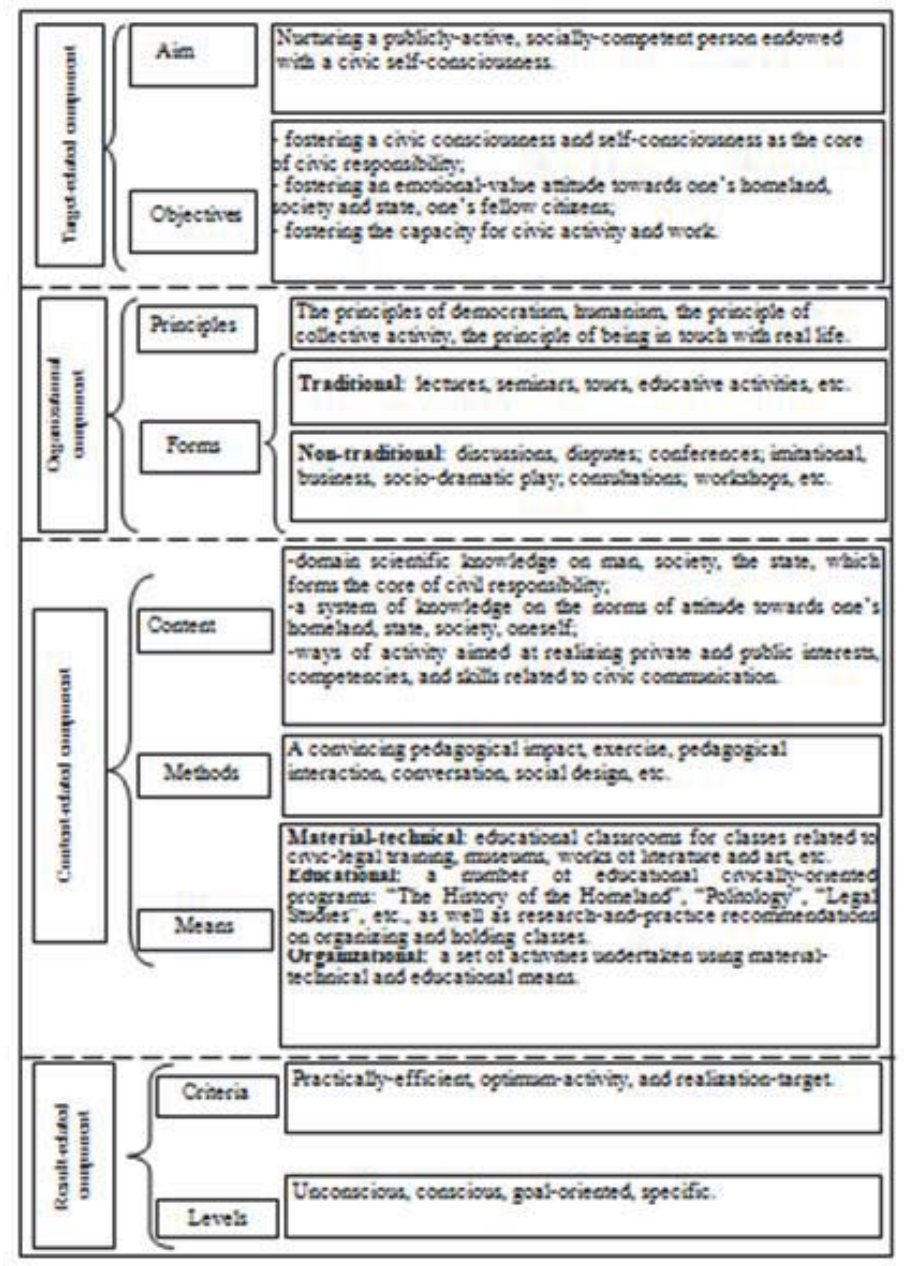

Figure 1. A model for the formation of a sense of civic responsibility in college students

In addition, the authors have determined pedagogical conditions that ensure the effectiveness of formation of a sense of civic responsibility in students: providing pedagogical support for students developing civic qualities during the course of educational and bringing-up work; realizing the technology of social design of classes aimed at fostering civic responsibility in students; conducting a cycle of scientific-methodological seminars for college instructors on issues in fostering civic responsibility in students; creating a special educational environment. "In any event, the environment has a major impact on bringing up a citizen. The environment approach towards fostering one's civics characterizes the peculiarity of this process ", but "the main condition for the success of civic education is the proper organization of the learning process and creation of conditions for fostering one's moral making, proper development, and sense of being 
successful" [11]. In that study, the authors mainly relied on the subject-oriented approach, since "it ensures freedom of choice of the content of education with a view to meeting not just the educational but spiritual, cultural, and life needs of a person" [12], which is crucial to the formation of a sense of civic responsibility in students.

The authors have worked out and tested the diagnostics of the degree to which a sense of civic responsibility has been developed in students, which includes the practical-efficient, optimum-activity, and realization-target criteria and the unconscious, conscious, goal-oriented, and specific levels, which are provided in the integral model (Figure 1).

\section{Conclusion}

Civic education is a goal-oriented, specially organized process of formation of sustainable civic qualities in youth. Based on the results of their study, the authors have arrived at the following conclusion.

During the course of the study, it was established that the aim and result of the civic education of students within the system of their professional preparation is a civic culture, which is construed by the authors as an integrative quality of a person, which is characterized by students possessing in-depth and sound knowledge in the area of the civil education of students; a value attitude towards one's homeland, one's people and its culture, representatives of other ethnicities and their culture, the state's political-legal sphere, society and common human issues; a positive mindset towards professional activity in the area of civic education.

The authors have revealed the characteristics of organizing the civic education of students in the system of professional preparation, which are associated with the unity of the person-oriented and professional components of professional preparation; the integration of its theoretical, methodological, practical, and scientific-research spheres; the special significance of the patriotic, political-legal, national, international, and common human aspects of civil education for young people; the complex nature of the aim of civic education, which is manifested in the unity of scientific knowledge, value relations, and practical activity.

The effectiveness of formation of a sense of civic responsibility in the personality of students, which is manifested in one's readiness to take part in enhancing modern society and make an impact on the country's social-political life, can be attained in the educational environment of colleges in meeting the following conditions:

- including issues related to civic-patriotic education among the top-priority objectives of education and bringingup in college;

- fostering in students a motivational-value attitude towards the process of formation of a sense of civics as a person's integrative quality oriented towards the real conditions of present-day life;

- enriching the content of education through introducing in the educational process moral-creative and culturalcreative functions and using the potential of social-humanities and psychological-pedagogical disciplines;

- boosting the role of the college instructor's personality, his/her apprehension of pedagogical targets, values, and principles;

- humanizing and humanitarizing education, which is based on that the college student is a conscious, independent person with self-esteem and a sense of responsibility;

- fostering a culture of international communication, the ability to resolve possible interethnic conflicts through soft, rather than hard, power.

The effectiveness of the process of civic education in the system of professional preparation of students is ensured through the consistent realization of the set of interrelated components in the model for civic education.

\section{Inferences}

1. The authors construe the civic responsibility of college students as one's ability to conduct one's activity relying on a sense of civic duty, as well as in correspondence with the norms of civil behavior accepted in society.

2. The pedagogical conditions for the formation of a sense of civic responsibility are: providing pedagogical support for students developing civic qualities during the process of educational and bringing-up work; realizing the technology of social design of classes aimed at the formation of a sense of civic responsibility in students; conducting a cycle of scientific-methodological seminars for college instructors on issues in the formation of a sense of civic responsibility in students.

3. As means of pedagogical control and self-control over the degree to which a sense of civic responsibility has been developed in students, the authors have worked out and tested various questionnaires, tests, and a map for the study of civic responsibility in students. 
The authors feel that further research into issues related to the specificity of civic responsibility in pedagogical science, as well as the development of methodologies and technology for fostering it, is an objective to be pursued in the observable future. The subject of our next research can be the study, development, and testing of innovative forms and methods of pedagogical activity aimed at the formation of a sense of civic responsibility in students.

\section{References}

The Importance of Civic Education. Date Views 16.07.2014 www.democracyandsociety.com/blog/2011/06/26/the-importance-of-civiceducation/.

What is Civic Education? Date Views 16.07.2014 www.mdk12.org/instruction/curriculum/social_studies/what_is_civiced.html.

Bim-Bad, B.M., 2002. Pedagogical Encyclopedic Dictionary. Moscow: Great Russian Encyclopedia, pp: 528.

Yarullin, I.F. and R.R. Nasibullov, 2014. Formation of Future Teachers' Civic Responsibility in Contemporary Society. Life Science Journal, 11(10s): 311-315.

Glossary Commander. Date Views 16.072014 www.glossary.ru/cgi-bin/gl_sch2.cgi.

The Role of Civic Education. Date Views 16.072014 www.civiced.org/papers/articles_role.html.

Civic Education. Date Views 16.072014 www.civicyouth.org/quick-facts/quick-facts-civic-education/.

Crittenden, J. and P. Levine. Civic Education. Date Views 16.072014 www.plato.stanford.edu/entries/civic-education/.

Rietbergen-McCracken, J. Civic Education. Date Views 16.072014 www.pgexchange.org/index.php?option=com_content\&view=article \&id $=133 \&$ ltemid $=122$.

Yarullin, I.F. and R.R. Nasibullov, 2013. On Fostering Civic Responsibility in College Students. Kazan: Kazanskiy Universitet, Obrazovaniye i Samorazvitiye: Nauchno-Predagogicheskiy Zhurnal: 4(38): 101-106.

Pshonko, V.A. Civic Education in the System of Nurturing Social-Personal Qualities in College Graduates. Date Views 16.07.2014 www.smolpedagog.ru/article\%2018.html.

Nigmatov, Z.G. and L.R. Shakirova, 2013. College Learning Theory and Technology: A Set of Lectures. Kazan: Kazanskiy Universitet, pp: 464. 